Spreadsheet software as a teaching and learning tool: perspectives from an undergraduate financial modelling subject

\author{
Rafiuddin Ahmed*
}

This paper is the author's private copy of the final submission to the journal of Review of Higher Education and Self Learning (RHESL). Publication details: Review of Higher Education and Self Learning, Vol 1, Issue 1, pp. 54-75 (2008).

*Address for correspondence: rafiuddin.ahmed@jcu.edu.au ; Lecturer, School of Business, James Cook University, Douglas, QLD 4811, Australia. 


\title{
Spreadsheet software as a teaching and learning tool: perspectives from an undergraduate financial modelling subject
}

\begin{abstract}
Technology based teaching of accounting curriculum is widely researched by accounting educators. This paper reports the findings of the use of computers and Microsoft Excel spreadsheet program as a means to reflect on, and to enhance prior learning, of financial accounting, managerial accounting and finance concepts and problems, through a financial modelling subject, in an undergraduate program in an Australian regional university. Data were collected from the researched university's formal feedback systems, Student Feedback on Subjects (SFS), and archived course materials, over a three year period (2003-2005). Using pattern matching approach (Yin, 2003), data were analyzed for making generalizations about the effectiveness of spreadsheet software usage as a pedagogical and educational tool. The study finds that spreadsheet based teaching and learning equip students with computer literacy, and spreadsheet application skills in the areas of management accounting and finance. The study also finds that the students with a few years' of work experience outperform the students without any work experience, and appreciation of the course among the students without work experience is lower than their counterpart with a few years' of work experience. The study has implications for accounting educators, in that difficult to learn accounting and finance concepts can be taught using a spreadsheet based modelling subject; this can provide significant insight into the relationships among numerous variables, which are difficult to manipulate and solve manually, in a traditional chalk and talk teaching environment.
\end{abstract}

Keywords: Microsoft Excel, cognitive thinking, constructivism, financial models, accounting education. 


\section{Introduction}

The use of computers in accounting education has been a contentious issue from the inception of the use of computers in the academic and professional environments. The accounting academics and practitioners have concurred: computers should be part of a teaching and learning tool For example, the requirement to use computers in the accounting curriculum was researched in the late 1990s (Kent \& Linnegar, 1988) and the requirement is still recommended for teaching and learning purposes (Nia \& Nadine, 2006; Satoshi \& Gregory, 2006; Tracey \& Beverley, 2006). In recent times, educators have been using different application softwares to deliver, and teach subject materials; especially spreadsheet software packages are being used to teach a diverse range of courses and to equip students with the skills and expertise to enter the workforce (Carol \& Borthick, 2007; Dennis, 2004; lan, Erwin, \& Peter, 2005; Moshen, 2003; Neil, 2004; Theuri \& Gunn, 1998).

Though accounting educators are using computers and software packages to deliver and teach subject materials, the effectiveness of the approach is tested from the teacher's perspective only (except Neil, 2004). Besides, the literature on the use of computers, and spreadsheet packages is replete with issues encountered by the academics; most of these are anecdotes of the staff teaching the subject, or teachers teaching only a few topics where computers in general, and spreadsheet packages in particular, are used to solve few assessment tasks. There is a dearth in research on subject materials that are blended with related management accounting and finance topics, and the effectiveness of the subject, both from the teacher's perspective, and the students' perspectives, beyond a one year time period. This study is aimed to address these deficiencies by addressing the following research questions:

a) How does a teacher perceive the use of computers and a spreadsheet package to deliver and disseminate teaching materials?

b) Why does a teacher blend the subject materials with few topics from a few previously completed accounting and finance units, and design the subject materials to develop generic skills for subsequent use in the degree and for future employment?

c) How do the students enrolled in a blended subject perceive the use of computers and a spreadsheet package to learn and grasp the subject materials for their degree and for future employment?

d) Why do the students perceive the effectiveness of the blended subject materials in a certain way, either positively, or negatively?

In order to address the research questions, prior research, on the use of computers and the spreadsheet packages, is reviewed; the review however, did not seem sufficient to inform the underlying rationale behind the use of computers and spreadsheets in accounting education. So, two other theories were used to supplement the analysis: the Gestaltian cognitive psychology of learning (Borthick \& Clark, 1986) and the constructivist theory of learning (Neil, 2004), both of which were studied in the context of accounting education. Using a case study approach, this research is conducted in a regional university in Australia where the subject was taught in three consecutive years, between the years 2003-2005.

The study has made a number of contributions to the growing body of the literature on the use of technology in accounting education: firstly, the teacher and the students perceived the usefulness of computers as part of a degree from two opposite perspectives, the teacher perceives that the use of the computer is beneficial, whereas the students perceived that the use of computers was minimally beneficial Secondly, the teacher perceived that the use of a spreadsheet package is a wonderful platform to deliver and disseminate complex knowledge for lifelong learning, whereas the students missed the apparent connections among the uses of spreadsheets, the problems learned and the generic skills to be retained for other subjects, and for their future employment Thirdly, the teacher perceived that designing and developing the subject would be useful if learning theories were consulted and aligned to subject 
materials, however, the students did not perceive that the deeply rooted learning theory backed curriculum mattered much in their learning of the subject materials.

The remainder of the paper is structured as follows: in section two, the relevant literature is reviewed, in section three, the theoretical framework is developed, in section four, the research method is discussed, in section five, the case is described, in section six, the findings are discussed, and in section seven, the conclusions are drawn.

\section{Computers, spreadsheets and accounting education}

\section{Computers in accounting education}

The computer is widely used in accounting education from the early 1990s (Borthick \& Clark, 1986; Collier, Kaye, Spaul, \& Williams, 1990; , 1988; Rachlin, 1981), its use has been growing to such an extent that some educational institutions are thinking of mandatory use of computers in classroom learning environment (Lawrence \& Rebecca, 2003). Academics find computers as useful tools to deliver teaching materials or supplement teaching materials in a virtual learning environment; as a result students are finding the use of computers as an essential educational tool (Borthick \& Clark, 1986; Hossein \& Abdus, 2005; Nia \& Nadine, 2006; Paul \& Timothy, 2007). Computers are used in accounting education to teach advanced problems, system design issues, assess students, provide feedback and ensure better accountability (Paul \& Timothy, 2007).

Accounting educators have considered computers as a reliable pedagogical tool that can enhance their teaching abilities effectively; be used to teach software and system design principles, or as an aid to impart knowledge which is impossible to disseminate in a traditional chalk and talk teaching environment. For example, accounting educators have used computers to teach the Accounting Information System (Alexander, 1996), auditing (Choi, 1993; Michelle, 2005; Philip \& Mark, 2000; Robert, Kurt, \& Jian, 2002; Ulric, Elliott, \& Jay, 2001), finance (Dennis, 2004; Kruck \& Maher, 1999), and Financial Accounting (Maher, 1993; Mark \& Clyde, 2003). The educators have placed emphasis on students' developing abilities to use software programs or learn computer games to promote deeper understanding of course materials (Andreas, 2005; Michelle, 2005). For example, Alexander (1996), Kruck and Maher (1999) have used general spreadsheet design principles to equip students with spreadsheet design skills. Accounting educators also claim that the use of computers enhances students' motivations to use computers as a learning tool, which in turn, can improve their performance in exams (Tracey \& Beverley, 2006), however, an earlier study by Borthick and Clark (1986) found that the use of computers for learning didn't influence exam performance. Nonetheless, students prefer to see that their lecturers use computers to teach and deliver teaching materials. Students also develop a positive attitude towards tutors and their presentations when computers are used to present and deliver teaching materials (Hossein \& Abdus, 2005). While academics think that they have done a great job by incorporating computers in the curriculum, students, as recipients of computerised instructions, may have different views about their uses of computers as an educational tool.

Students largely perceive the computer as an educational instrument that is a complement to classroom learning. Accordingly, their perceptions vary by their need to learn the concepts and practices of subject materials with computers. For example, Borthick and Clark (1986) found that students show a positive attitude towards the use of computers in the early part of a session, however, this attitude wanes with the progress of the semester. Borthick \& Clark (1986) and Tracey \& Beverley (2006) argued that students viewed computers as a performance enhancing instrument that can quickly provide them with insight into the complex relationships among the variables in a complex problem or case study or even give them an opportunity to receive instant feedback on attempts to solve problems. Over the years, accounting educators have placed emphasis on students' use of computers to learn course materials through different integrative assessment tasks and encouraged students to achieve good functional knowledge of different application softwares by embedding computing skills and prior learning in other subjects. For 
example, Kruck and Maher (1999) and Patricia (2005) argued that computers can be used to enhance prior learning in accounting and finance subjects.

Despite the push from accounting educators, access to computers or the desire of the students to use computers in different countries revealed differing student characteristics about the use of computers in learning course materials. For example, Fink (1998) reported that Australian and New Zealand students in a computer auditing course spent less time in learning computer skills required in a computerised auditing course, than their counterpart in the US and Canadian universities. Though limited access and cost were issues for not being able to use computers in accounting education (Kent \& Linnegar, 1988), the cheap availability and wider access to computers in recent times have made it possible to use computers for accounting education (Lawrence \& Rebecca, 2003). More research is being carried out in different parts of the world about the educational value of computers in enhancing students' learning from classroom teaching, integration of computers, subject materials and assessment tasks. Researchers have even gone beyond the intrinsic use of computers in enhancing students' learning capabilities. For example, Borthick and Clark (1986) and Neil (2004) examined the impact of computer use on students' learning from cognitive psychology and constructivist's pedagogical theory and concluded that students' thinking abilities are significantly enhanced by the use of computers when the computers are used for learning subject materials.

\section{Spreadsheet in accounting education}

The introduction of spreadsheet software has revolutionised instruction in classroom teaching and learning from the inception of computers. An spreadsheet program like Excel has been used for decades as a pedagogical aid, as a skill building tool, as a platform to build teaching materials and to learn difficult problems which are otherwise impossible to learn in a chalk and talk environment. Its popularity has been increasing exponentially. For example, Horngren, Datar \& Foster's (2006) cost accounting textbook and Ross, Westerfield \& Jordan's (2004) business finance textbook have end of chapter exercises requiring the use of a spreadsheet program.

An spreadsheet is largely used as a pedagogical tool to deliver teaching materials and equip students with the much sought after computer literacy skills. Accounting educators have used spreadsheet programs to develop students' computing skills and spreadsheet skills. For example, the spreadsheet is used to teach spreadsheet design skills (Alexander, 1996), teach concepts of finance (Dennis, 2004), teach general computer literacy (Mark \& Clyde, 2003), and to teach skills to embed word and excel into problems solving, and interpretations (Teets \& Desmond, 1995). Accounting educators have integrated different course materials and spreadsheets, embedded spreadsheet tasks with course related problems so that the students learn spreadsheet applications to real life problem contexts. In such situations, the spreadsheet is seen as an instrument through which students could grasp the course materials and visualise the link between the applied aspects of problems and the underlying concepts of the course materials. For example, students learned hands on spreadsheet design skills in an AIS course (Alexander, 1996), spreadsheet modelling in financial modelling course (Kruck \& Maher, 1999), and algorithmic thinking through a modelling course (ljiri, 1983; Neil, 2004).

Some educators even think that working on problems in spreadsheets is a good brainstorming exercise which promotes enjoyment and deep learning. For example, Neil (2004) and Borthick and Clark (1986) argue that spreadsheets promote deep learning and algorithmic thinking in the students, and students enjoy working on spreadsheet models to learn course materials. Some academics even think that computer games and spreadsheet based games can foster students' learning of spreadsheet skills and course materials. For example, (Andreas, 2005) cited the use of CALVADOS game to teach opportunity costs, relevant costs and transfer pricing in a managerial accounting course, and (Michelle, 2005) cited the use of Who Wants to Be (WWTB) to teach auditing course material. Both researchers reported positive learning experiences by the students when the games are used to teach subject materials. The use of the spreadsheet as a pedagogical tool goes far beyond an educator's involvement in guiding students' learning of detailed skills embedded through assigned course materials. 
Numerous studies have reported that students learn an array of detailed spreadsheet skills through different courses. The skills are generic and can be applied to different problem contexts, and in different subjects, the educators teach these skills or the students spend time to learn these skills to use in jobs. For example, students can use spreadsheet programs to learn risk analysis skills (Dennis, 2004; Kelliher, Fogarty, \& Goldwater, 1996; Togo, 1992), design and error detection skills (Alexander, 1996; Heagy \& Gallun, 1994; Ian, Erwin, \& Peter, 2005), develop algorithmic thinking skills (Borthick \& Clark, 1986; Neil, 2004), memorisation and integrations skills (Alexander, 1996; Kruck \& Maher, 1999; Teets \& Desmond, 1995), and scenario analysis skills (Alexander, 1996; Dennis, 2004; Togo, 1992). In recent times, the spreadsheet is being used extensively to develop financial models that require integration of finance, cost accounting, financial accounting concepts and spreadsheet functions to build and design useful decision models (Read \& Baston, 1999)(Kruck \& Maher, 1999). This integration has enabled the educators to teach and expose students to advanced problem solving skills where immediate feedback on attempted problems, and error checking are possible.

\section{Theoretical framework}

\section{Gestaltian cognitive theory of learning}

Educational psychologists have proposed different psychological theories of learning. Gestaltian psychological theory of learning is one of these theories of learning (Neil,2004). The Gestaltian approach to learning was explored in understanding the learning style of accounting students (see for example, (Borthick \& Clark, 1986; Neil, 2004). In Gestaltian tradition, students learn differently by following personal learning styles. As opposed to learning problems and trying to memorise them in a rote way, students learn the underlying rules and procedures and then apply these rules and procedures to different problem scenarios: such learning is generic and can be retained longer (Borthick \& Clark, 1986). Werheimer (1959) termed such learning as productive thinking and more generalizable (Borthick \& Clark, 1986).

Gestaltian psychology of learning has provided insight into the approach to problem solving, and integration of theory with problems. Students following this tradition gain insight into the structure of a problem, analyse the relationships among different variables, and solve the problems by iterations. For example, in an algebraic equitation students manipulate different solutions to derive the unique solution (Neil, 2004). A student learns and solves the problem by organising the components of a problem, and derives the solution in few steps.

While the Gestaltian tradition focuses on lifelong learning of generalizable problem solving skills, it does not provide insight into alternative meanings into the solutions. In reality, students comprehend the underlying principles of solutions in different ways; as a result they solve an array of equally plausible and acceptable solution sets. Gestaltian tradition implies a unique and objective solution set for problems through different cognitive mapping processes followed by different students. In order to learn aspects of problems for lifelong use, students need to explore the literal solutions to problems, and perhaps understand the alternative meanings of problems and solutions. An alternative theory, constructivism, provides an insight into students' approaches to problem solving and interpretation, at an individual and group level.

\section{Constructivist theory of learning}

Constructivist learning is a recent addition to epistemology and has different connotations. Vrasidas (2000) has summarised the major philosophical and epistemological assumptions of constructivism as follows:

(a) We can experience everything within the boundary of a real world;

(b) Structure of the world is created through interaction and interpretation;

(c) The mind creates symbols by perceiving and interpreting the world;

(d) Human thoughts are imaginative and develop out of perception, sensory experiences and social interaction; and

(e) Meaning is a function of interpretation, experience, and understanding of a knower. 
These assumptions have implications for a learner, in that a learner exploring and interacting with the reality, the environment, and society will continually endeavour to search for truth or meaning. There are two different ways knowledge can be constructed: personal and social. Piaget (1970) and Von Glaserfeld (1989) argue that a personal constructivist constructs knowledge in the brain through reorganization of experiences and cognitive structures (Vrasidas, 2000). This implies that personal knowledge construction efforts and interaction with outer world shapes his/her understanding and interpretation, this process of knowledge construction is dynamic. On the other hand, the social constructivist constructs knowledge in communities of practice through social interaction (Brown, Collins \& Dugavid, 1989; Khun, 1996).

\section{Research method}

A case study approach is chosen to conduct this research. A case study approach is widely used in accounting education studies (Lawrence \& Rebecca, 2003; Neil, 2004). Kaplan (1986, p. 429) argues that to capture the complexity of cost accounting and management control systems, case study research enables a researcher to capture a rich description of the context within which the complex organizational problems are located; in this study, computers and spreadsheets, as teaching and learning tools, are identified as complex phenomena to study and explore because of ongoing debates about the usefulness of computers and spreadsheets by the educators.

Any case study requires a few steps to be followed for the successful completion of a project. This study has followed a few of the steps suggested in Ryan, Scapens \& Theobold (1992). Firstly, the subject was identified as a potential subject for research because it was unlike the other traditional subjects taught in the university's accounting curriculum; it was also studied to explore the effectiveness in lifting the skills and expertise of the students and the staff members so that the insights could be transferred to the other subjects where the computer and software packages could be integrated as an educational tool.

In order to examine the research issues multiple data sources were used. Multiple sources of data improve the validity and reliability of the results obtained from a field (Patton, 2002; Yin, 2003). Two sources of data were used: the data held by the researcher/teacher between the years 2003 and 2005 this included the subject guide, the subject resources, the software packages, personal diaries maintained throughout the semester on key teaching and learning issues, and email correspondence with the students during the semesters. The other bundle of data related to the students and were: the formal evaluation of the subject by the university (between the years 2003 and 2005), qualitative comments on 11 different aspects of the subject and the teaching, the emails from past students who completed the subject and entered the workforce, informal discussion with the past students who completed this subject, informal discussion with the staff from local accounting firms, the tutors assigned to the workshops, and the instructor from the other campus of the university.

Analyzing evidence is a means to reach the conclusions or developing theory from a case study research (Eisenhardt, 1989; Ryan, Scapens, \& Theobald, 1992). Data collected from the field needs to be analysed to make valid and reliable conclusions from a case study (Ryan, Scapens, \& Theobald, 1992). Data collected from multiple sources are analysed to improve the validity and reliability of the conclusions reached in this paper. In this study, collected data is analysed by using the time series data analysis technique (Yin, 2003).Time Series Analysis is used to analyse case study evidence (Yin, 1994, pp. 113118). In case studies, the relationships between variables, or changes in constructs or events are studied over time for building a cause and effect relationship. The data was analysed using two common qualitative data analysis techniques: coding and content analysis. In order to improve the analysis further, evidence on the same issues are corroborated using the triangulation approach to evidence assessment (Ryan, Scapens, \& Theobald, 1992).

The findings from the site are generalized to the university's formal institutional educational environment only (see for example, Patton, 2002; Yin, 2003). Mintzberg (1979 p. 585) argues that in-depth study of a small number of organisations is not a barrier to generalization. Rather, the depth of research is more important for making generalizations from data collected from the field. This study is an in-depth study of 
a single subject offered by one of the regional universities in Australia. The findings from this site may be useful in understanding the teaching and learning issues of other universities offering a similar subject over a similar timeframe.

\section{Financial modelling in a curriculum}

The subject of this research is a financial modelling subject taught over a three year time period, between 2003 to 2005, in an undergraduate program of a regional university in Australia. The student population of the university varied between the years, by gender, by work experience, and by the university entrance level scores. The subject was developed in the wake of a discussion between one of the new colleagues who joined the faculty from another university and this researcher. The staff members in the program concurred that a Business Modelling subject needed to be introduced to satisfy the professional accounting bodies, that is, the Certified Practicing Accountants of Australia (CPA) and the local accounting profession. At the time of the development of the subject, a few issues were kept in mind: the computer literacy of the students entering the degree, the skill sets constantly demanded by the employees and the profession, the abilities of the staff member to train the students in Excel and cover the subject materials, the availability of computers at the university, the completion of the pre-requisite subjects, that is, Accounting, Finance and Management Accounting. In late February 2003, the subject was adopted as a compulsory third year subject, only to be offered to the students who completed Introductory Financial Accounting, Introductory Management Accounting, and first Financial Management unit.

\section{The syllabi}

The contents of the subject were designed in a modular form so that the students could learn the contents sequentially. The subject comprised three modules: a generic spreadsheet module, a management accounting module, and a finance module.

\section{Spreadsheet module}

This module was taught to equip the student with the design issues of financial modelling. Students learned the scope of a generic financial model, the specifications of a model, the design of a financial model, actual building of a model, and finally testing and use of the model including documentation of the model for the employers. The majority of the students had essential computer literacy; however, the students did not have any knowledge about detailed design, building and documentation skills. In each of the lectures, the students were exposed to different generic ideas about model building Illustrative methods were emphasised to teach this module (ljiri, 1983). Diagram 1 below is an example of a generic model building exercise.

Diagram 1: A generic model design

\begin{tabular}{|c|c|c|c|c|c|c|}
\hline Ref No & Description & Ref No & Calculation Rule & Units & Example & Notes \\
\hline \multicolumn{7}{|l|}{ Inputs } \\
\hline Inp1 & Selling Price & & & & $\$ 74,500$ & \\
\hline $\operatorname{lnp2}$ & Units Sold & & & & 120 & \\
\hline $\operatorname{Inp} 3$ & Unit Manufacturing Cost & & & & $\$ 46,295$ & \\
\hline Inp4 & Selling \& Admin Cost as \% of Selling Price & & & & 0.33 & \\
\hline \begin{tabular}{|l|l|}
$\ln 55$ \\
$\operatorname{lnp} 10$ \\
\end{tabular} & $\begin{array}{l}\text { Panes Per Year } \\
\text { Projected Hourly Cost } 2 \\
\end{array}$ & & & & $\begin{array}{l}12 \mathrm{nnn}^{1} \mathrm{nnn} \\
\$ 338.25\end{array}$ & \\
\hline \multicolumn{7}{|l|}{ Calculations } \\
\hline \multirow[t]{3}{*}{ Calc1 } & otal Revenues from Sales & Inp1 & Selling Price & & $\frac{1}{74,500}$ & \\
\hline & & & & & & \\
\hline & & $\operatorname{lnp2}$ & Units Sold & & $120=8,940,000$ & \\
\hline \multirow{3}{*}{ Calc2 } & Selling and Admin cost per unit & & $=$ & & $=$ & \\
\hline & & Inp4 & Selling \& Admin Cost as $\%$ of Selli & ing Price & 0.33 & \\
\hline & & $\ln 33$ & - & & $46205=15,7735$ & \\
\hline
\end{tabular}

\section{The Management Accounting module}

In this second module, the students learned about the scope of spreadsheet usage to different applied aspects of management accounting. The topics from Management Accounting were selected so that the 
variables can be manipulated in an input, process, and output format (Read \& Baston, 1999). In this module, the students were expected to apply the skills and understanding of generic models, learned in module one. Using illustrations from each of the assorted chapters, some models were designed and built during the lectures; this was done so that the students could see the connection between modelling principles and modelling design applications, that is, the relationships between the variables and the outputs for decisions. For example, capital budgeting, cost allocations, and master budgeting are three most commonly used management accounting practices that were used in lecture sessions and for homework assignments. Homework assignments were to be done at home, either individually or in groups of two to three students to enhance firmer understanding of design, build and documentation principles of various financial models.

\section{The finance module}

In this module, some common finance topics were chosen for lecture and homework assignments. The topics were chosen to enable the students to manipulate numerical variables in Excel, and solve them. Some common financial modelling textbooks were consulted to pick and choose the topic areas. The object was to instruct the students in the chosen topics and guide them to apply these common models to real life problem situations or to similar problems they experienced in their workplace or were able to share with their peers who experience similar problems.

The problems in this module were taught to accommodate skill building, problem solving and interpreting, simultaneously. In the lectures, some examples were demonstrated to cover the financial models that embedded Excel skills, numerical solution skills, and interpretations of results from the financial models. Each problem had three distinct steps: gathering and interpreting the problem variables, applying the Excel functions through a model designed for the problem, and the interpretations of the results of the models. The in-class discussion and demonstration sessions followed homework items which were developed around similar problems. Some homework questions required the students to search the net to gather information from corporate websites, and to design models with those data.

\section{Discussion of the findings}

The findings from the field are classified and analysed from two distinct perspectives, from the teacher's perspective and from the students' perspectives.

\section{The teacher's perspective}

The discussion of the findings from the teacher's perspective is necessary to reflect on the perceived usefulness of the subject in meeting the objectives set for the students.

\section{Computer literacy in accounting education}

The study revealed that the students had apparent lack of computer literacy, so some sort of Computer Assisted Learning (CAL) was perceived useful (Tracey \& Beverley, 2006). Some of the students did not have exposure to micro computers at all while the other students were well versed in micro computers. The students appreciated the introduction of the subject because they thought that it was necessary for them to be able to use computers not only for their study of the subject but also other subjects planned for their entire university degree (Linnegar and Kent, 1988). They also needed to know computer usage for future employment as suggested by ljiri (1983).

\section{Spreadsheet knowledge in curriculum}

The study also revealed that the students in the subject lacked sufficient functional knowledge about spreadsheet software to be able to meet the objectives and tasks set for them. The use of spreadsheet software is perceived as a necessity , especially, the design and documentation issues were perceived extremely useful for these students (Alexander, 1996; Ian, Erwin, \& Peter, 2005; Kruck \& Maher, 1999). Students also showed enthusiasm to use spreadsheet for managerial accounting topics (Borthick \& Clark, 1986; Dennis, 2001) such as budgeting, and cash flow forecasting, Another cohort with strong finance orientation found finance topics quite beneficial to enhance their skills in finance (Dennis, 2004; Henk \& 
Michael, 1998; Kruck \& Maher, 1999; Mabey, Topham, \& Kaye, 1998; Togo, 1992). The use of spreadsheets gave the students opportunities to check their answers and receive feedback on their answers (Mark \& Clyde, 2003).

\section{Group and individual problem solving}

Piaget (1970) and Von Glaserfeld (1989) argue that learners can construct knowledge individually in a constructivist learning framework. The study revealed that the students needed to solve problems individually, and in groups. Because of the sheer size of the problems, that could not be done manually, due to huge involvement of time, the subject required the students to have a firmer understanding of manipulating spreadsheet designs tailored for different types of problems. This requires their cognitive thinking for optimal solutions. Most of the finance topics provided unique solutions, supporting the Gestaltian tradition of cognitive psychology of learning (Borthick \& Clark, 1986; Neil, 2004).

Some of the problems, could not be done alone however, so group members needed to be working on the problems in phases, and by dividing the tasks among themselves, and later putting the solution pieces together for the problems, this group work practice supports the constructivist learning philosophy in that the members of the group had different interpretations and understanding of the meaning of the problems and analysis of the solutions. The meaning of the problems and the solutions were created subjectively by different members of the groups. This group learning process in this study has revealed that the learners constructed knowledge in a community of practice and is consistent with the social constructivists' view of learning (Brown, Collins \& Dugavid, 1989; Khun, 1996).

\section{Prior theory and modelling}

Kruck \& Maher (1999), Tracey \& Beverley (2006) and Patricia (2005) argue that spreadsheet models require prior learning of theories and problems in accounting and finance subjects. Consistent with this, this study has revealed that the modelling subject required prior theoretical knowledge of accounting and finance concepts and problems. The students were asked to build spreadsheet models; the models required the students to apply theoretical understanding of concepts such as effective interest rate calculation, amortization of principal balance calculation, and present value of money concepts (Kruck \& Maher, 1999). The study also revealed that the students needed to know the concepts of risk for designing financial models in: capital budgeting, budgeted cash flows, and budgeted income statement (Dennis, 2004; Togo, 1992).

The study also revealed that prior knowledge of cost and management accounting topics were useful to build, design and analyse the models developed in the areas of cost allocation, cost volume profit relationships, budgeting, and variance analysis. The use of spreadsheets has enabled the students to manipulate huge volumes of data and concentrate on understanding the principles. This saved them huge amount of time, which they could then spend on understanding the concepts and principles underlying the financial models This is consistent with the earlier literature on spreadsheet modelling (Borthick \& Clark, 1986; Togo \& McNamee, 1995). However, there is contrary evidence that students find it difficult to manage time to learn spreadsheet skills and models simultaneously (Bagranoff, 1993). Academics also find it time consuming to learning necessary computing, spreadsheet or software skills to teach theories through different types of simulated financial games (Alexander, 1996; Andreas, 2005; Fink, 1998; Michelle, 2005; Togo \& McNamee, 1995).

\section{Modelling and lifelong learning}

Spreadsheet models equip students with lifelong skills that are beneficial for their degree and for future employment; the skills are generic and transferable across an array of tasks (Alexander, 1996; Kruck \& Maher, 1999; Neil, 2004; Tracey \& Beverley, 2006). Consistent with these arguments, the study has identified teacher efforts to equip the students with necessary spreadsheet skills, coupled with contextual problems in finance, accounting, and management accounting, so that the students learn through the problems generalizable skills for their degrees and future employment. Borthick and Clark (1986) and Neil (2004) specifically found that accounting students solve problems following the Gestaltian cognitive 
psychology tradition, that is, they learn principles underlying different problems and then apply those to solve those problems. Consistent with these arguments, the students in this research learned fundamental concepts and principles and applied those to advanced problems in management accounting and finance. The learning objectives support evidence to these effects. An extract of the subject of 2005 has revealed the following course objectives set by the teacher:

1. Critically evaluate the technical and theoretical literature on spreadsheet modelling;

2. Use Microsoft Excel at an intermediate to advanced level;

3. Apply prior knowledge in finance and management accounting to develop models using MS Excel 2002/2003;

4. Analyse, explain and interpret models and make recommendations to resolve issues raised in problems/cases assigned to the students;

5. Communicate effectively in interpersonal, group and cross cultural situations;

6. Communicate information effectively in written and in oral formats; and

7. Integrate your knowledge of MS Excel (2002/2003) and the assigned readings to analyse and interpret financial models to facilitate management decision making.

\section{The students' perspectives}

While the teacher perceived the use of computers, especially spreadsheet use, as important learning tools for advanced problems in management accounting and finance, the students' perspectives differed significantly. The findings from the students' perspectives are summarised below:

\section{Computer literacy in accounting education}

Two questions in the SFS evaluation questionnaire addressed this issue. The majority of the students enrolled in this subject between the years 2003 and 2005 were found to have expressed their reservations about the use of the computer as a learning tool; a small minority, however, found the use of the computer as a useful learning tool. Attendance, enthusiasm, and interaction with the peers, in the lectures and the workshops, were high - confirming the earlier findings (Borthick \& Clark, 1986).

Alexander (1996) and Kruck \& Maher (1999) argue that the use of computers, especially spreadsheets, is much demanded for work. This study, however, found otherwise: the majority of the students responded that they did not find the use of computers useful for their future employment. This was, perhaps, attributable to their high expectations from the subject, and exposure to computer in few other subjects as a part of assessment tasks. For example, in a compulsory undergraduate communication subject, the students learned the basics of micro computer use; Excel use, and Microsoft Word use for different assessment tasks. Despite the poor perceptions about the benefits of micro computer use for learning, a few comments were encouraging.

Out of all the subjects I have completed this subject has given me the most benefit in my employment.

The subject has given me a better ability to use excel.

This subject would be beneficial in the commerce degree.

\section{Spreadsheet knowledge in curriculum}

Spreadsheet skills in curriculum are useful to learn advanced problems in context bound subjects (Alexander, 1996; Borthick \& Clark, 1986; Kruck \& Maher, 1999). The majority of the students expressed their unhappiness about the quality of learning, that is, the use of Microsoft Excel to learn models in management accounting and finance, refuting the earlier claims that Excel is useful for learning. The evidence suggest that the students don't perceive Excel use in curriculum is as an enjoyable experience, contradicting Neil (2004) and partially contradicting Borthck \& Clark (1986) that the students' attitude waned with the progression of the subject. 


\section{Group and individual problem solving}

The use of Excel can promote group and individual problem solving (Borthick \& Clark, 1986; Neil, 2004) and reinforce learning of principles in a subject (Carol \& Borthick, 2007); the study evidence (the final overall grade in the subject) confirmed these earlier findings. The involvement of the students in individual problem solving each week in the workshops, through the semester for different assessment tasks, required the students to develop and enhance cognitive thinking skills, confirming the Gestaltian approach to learning (Borthick \& Clark, 1986), 'algorithmic' thinking skills (ljiri, 1983), and constructivist approach to individual learning (Piaget, 1970; Von Glaserfeld, 1989). Some reflective comments of a students, who enjoyed the subject made some positive remarks:

This is a very useful subject, I enjoyed the hands on.

One of the students had some other suggestions to broaden the scope of the subject:

The primary focus of the course was the development of the financial models using [E]xcel. ...I think that there is scope to include database management software such as [A]ccess. The course could accommodate this content without distracting from the modelling focus and would prepare graduates for their employment.

The constructivist theory advocates posit that learning takes place in groups of community practices (Brown, Collins \& Dugavid, 1989; Khun, 1996). The assessment tasks, especially the group problems, required the students to work in groups and submit the assessment as group assignments; students submitted their group assignments and performed better than they could had the assignments been submitted as individual work, confirming the effectiveness of the constructivist learning approach. Though the majority of the students had negative experiences about carrying disproportional workloads in group assignments, confirming the caveats in Neil (2004) about group problem solving, group assessment tasks were still an enjoyable experience to a few..

This is the most interesting subject to date.

A few could not agree on the usefulness of group and individual problem solving activities in workshop sessions, their perceptions about the subject accordingly were influenced by their frustrations about the organisation, the assessment, and the learning structure of the subject.

I felt that this subject was poorly organised

There was no structure to the subject

... (h)e has... to help when my group does not show up for workshops...... I am too scared to go to the workshops because I don't deserve to be treated like I am nothing.

The evidence above suggests that the meaning of 'organisation' was different to the students, the students perceived that the subject would be organised in a traditional way: a textbook would be there, some worked out example would be used to illustrate the concepts and exercises; there would be solutions to each end of the chapter questions and so on. The findings contradict the Gestaltian tradition of learning because the students thought that the course materials and the problems needed to be structured for them in such a way that they would be able to save significant time to solve and interpret the meaning of the problems (Borthick \& Clark, 1986; Carol \& Borthick, 2007; Neil, 2004). There were better students in the class; one such student endorsed the existing structure of the subject.

If the students attended all lectures and workshops and listened carefully to what the lecturer was explaining you would get a very good grasp on what he wanted however if students were too lazy. 


\section{Prior knowledge and modelling}

Kruck \& Maher (1999), Tracey \& Beverley (2006) and Patricia (2005) argue that spreadsheet models require prior learning of theories and problems in accounting and finance subjects. Partially supporting these arguments, this study finds that the students were divided: the majority of the students stated that contextual grounding of managerial and finance subject was a wastage of time, to a few, the subject was an enabling subject that was an 'acid test' of prior learning of management accounting and finance subjects; the students in this category had significant work experience or experience of using Excel for everyday work. Though these (positive) students were not specific about any topic or content of the subject, their endorsements about prior learning in management accounting and finance subjects were consistent with the earlier literature (Dennis, 2004; Kruck \& Maher, 1999; Togo, 1992); these students had, however, a different view about the difference between work practices and principles taught in the subject.

There is a big difference between the theory and the prac.

\section{Modelling and lifelong learning}

Spreadsheet models equip students with lifelong skills that are beneficial for their degree and for future employment; the skills are generic and transferable across an array of tasks (Alexander, 1996; Kruck \& Maher, 1999; Neil, 2004; Tracey \& Beverley, 2006). Consistent with these arguments, the study has identified that the students had a firm grasp of modelling concepts and were able to apply the principles learned to build, design and develop the models, and analyse the outputs produced by different models, assigned in the workshops, or in group assessment. For example, the failure rate in the subject overall was significantly lower than the other compulsory third year subjects. The students, however, needed initial teacher support along the way to complete their group assignments. Diagram 2 is an extract from assignment on cost of capital, requiring the students to plot a graph to a pair of airline companies' weighted average cost of capital. The students did not have any difficulty in completing this assignment.

\section{Diagram 2: cost of capital graph}

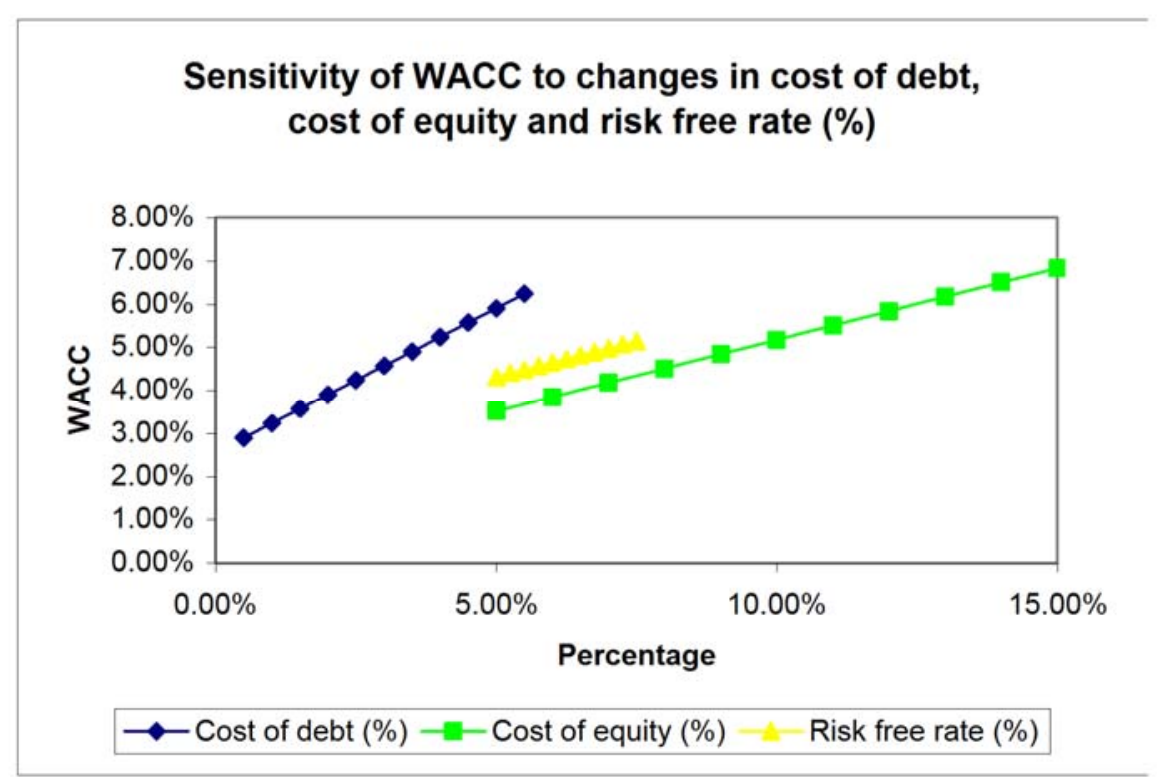

The plotting of the graph required the Gestaltian cognitive thinking abilities of the students (Borthick \& Clark, 1986; Carol \& Borthick, 2007), the interpretation of the efficient portfolio part endorsed the generic individual and group learning approach of the constructivist learning theory (Piaget, 1970; Von Glaserfield, 1989), and specific attributes of accounting students' use of the Constructivist learning approach to work individually and in groups to solve assigned problems (Borthick \& Clark, 1986; Carol \& 
Borthick, 2007; Neil, 2004). It is difficult to testify if learning outcomes claimed by the teacher/researcher (as outlined in the outline of the subject) have been achieved, a few reflective unsolicited email correspondences, however, provided support that the students were able to further their skills in their jobs.

\section{Conclusions}

This case study has explored the uses of computers in general, and spreadsheet packages in particular, in teaching and learning a third year financial modelling subject, in a regional university in Australia. The evidence is analysed from two opposing perspectives: from the teacher's perspective, and the students' perspectives, the findings from the teacher's perspective confirm earlier literature; however, the findings of the students' perspectives were mostly contrary to earlier findings.

The findings of the teacher's perspective have made three additions to extant research. The first finding is that the teacher prefers to use computers to teach subject materials. The teacher/researcher in this study was specifically instructed to develop this subject requiring the use of computers, the professional accounting bodies and the local accounting bodies also recommended to develop a subject requiring the use of computers in teaching. The second finding is that the teacher foresees beneficial uses of spreadsheet skills to disseminate subject materials, and to equip students with an array of skills expected in employment. The subject materials covered advanced problem solving and interpretation of solutions, both were congenial to adoption of the Microsoft Excel spreadsheet package to teach subject materials that cannot be taught in a traditional chalk and talk environment, because these problems are too time consuming and almost impossible to manipulate unless Excel is used. The adoption of Microsoft Excel is also justified from the Gestaltian cognitive psychology perspective, and the constructivist philosophy of teaching, in that deductive problem solving and subjective interpretations of the meanings of problems were part of the teaching of the subject. The third finding is that multiple theoretical perspectives need to be considered to design and develop curricula for lifelong learning. This is to enable the teacher to understand the logic behind teaching subject materials that will address the students' cognitive thinking needs, learning construction approaches, and understanding plausible meanings of 'illustrative learning' (ljiri, 1983). The assignments and the other assessment tasks in this study have addressed these theoretical issues. While the teacher's perspective is claimed to have novel objectives to foster students' learning, the students' perspectives have provided contrasting pictures.

The findings of the students' perspectives have made four major contributions to the literature on the use of computers in general and spreadsheets in particular, in learning subject materials. The first finding is that the students have identified the need to use computers with mixed enthusiasm, this is contrary to the literature to date. Perhaps, the cheaper availability, and the requirement to learn computers in schools, might have waned the students' interest in using computers to learn the subject; the ability to use computers as an essential learning skill might be the other plausible reasons as to why the students lacking enthusiasm did not rate the use of computers high as a learning tool. The second finding is that the majority of the students did not find Excel as a useful tool to learn the subject material, which is a concoction of Microsoft Excel, management accounting and finance topics; unlike conventional subjects taught in the universities, this subject was fairly open ended and unstructured, requiring the students to use their cognitive thinking skills, and algorithmic thinking skills to solve and complete assessment tasks individually, and in groups; the subject also required the students to interpret and understand the meaning of solved problems, the students needed construct knowledge in groups, and individually. The fourth finding is that the subject instilled lifelong learning into the students' brains, through the development of transferable skills to real life problems. The group assessment tasks required the students to brainstorm on management accounting and finance related problems, and then derive solutions by applying Microsoft Excel spreadsheet skills. Microsoft spreadsheet modelling skills are demanded by employers for routine daily use, and for decision making in various spheres of organisational decision making.

The study has the inherent limitations of a case study research project. Firstly, the study is a study of a single subject offered in a single educational institution, over a three year period, between the years 2003 and 2005. The generalizations made from this study are, thus, based on one single case study unit over a 
number of years, and may lack wider applicability; Mintzberg (1995) however, argues that findings from a single case study site don't pose any problems for generalization.

The findings of this study can be replicated in other institutions or other educational settings or even in other disciplines where a subject is blended with multiple topics from related or unrelated areas of a discipline. The study can also be extended to include other theoretical perspectives to understand students' learning styles or teachers' teaching styles, or curriculum design issues. One such theory may be hermeneutics where a researcher endeavours to understand and interpret students' understanding of subject materials based on prior grounding of other subjects or course materials. The study may be conducted using statistical survey instruments for improved validity, and reliability.

\section{References}

Alexander, R. A. (1996). Teaching good systems design for spreadsheet projects. Journal of Accounting Education, 14(1), 113.

Andreas, H. (2005). Calvados-A Business Game for Your Cost Accounting Course. Issues in Accounting Education, 20(1), 63.

Bagranoff, N. A. (1993). Adopting commercial software in the accounting classroom: A focus on learning. Journal of Accounting Education, 11(2), 275.

Borthick, A. F., \& Clark, R. L. (1986). The Role of Productive Thinking in Affecting Student Learning with Microcomputers in Accounting Education. The Accounting Review, 61(1), 143.

Carol, W. S., \& Borthick, A. F. (2007). Improving Performance in Accounting: Evidence for Insisting on Cognitive Conflict Tasks. Issues in Accounting Education, 22(1), 1.

Choi, F. D. S. (1993). Accounting education for the 21st century: Meeting the challenges. Issues in Accounting Education, 8(2), 423.

Collier, P. A., Kaye, G. R., Spaul, B. J., \& Williams, B. C. (1990). The Use of Computers in Accounting Courses: A New Perspective - A Comment. Accounting and Business Research, 20(80), 353.

Dennis, F. T. (2001). A curvilinear approach to teaching learning effects for cost estimation. Journal of Accounting Education, 19(3), 211.

Dennis, F. T. (2004). Risk analysis for accounting models: A spreadsheet simulation approach. Journal of Accounting Education, 22(2), 153.

Eisenhardt, K. M. (1989). Building Theories from Case Study Research. Academy of Management Review, 14(4), 532-550.

Fink, D. (1998). Advanced information systems auditing: A case study in course design and evaluation. Accounting Education, 7(1), 21.

Heagy, C. D., \& Gallun, R. A. (1994). Recommended microcomputer knowledge for accounting graduates: A survey. Journal of Accounting Education, 12(3), 205.

Henk, B., \& Michael, E. B. (1998). Instructional case: Evergreen Forests Limited. Issues in Accounting Education, 13(4), 869.

Horngren, C. T., Foster, G., \& Datar, S. M. (2006). Cost accounting : a managerial emphasis (12th ed.). Upper Saddle River, N.J.: Prentice Hall/Pearson Education International.

Hossein, N., \& Abdus, S. (2005). The effect of PowerPoint presentations on student learning and attitudes. Global Perspectives on Accounting Education, 2, 53.

Ian, B., Erwin, W., \& Peter, K. (2005). The impact of training in financial modelling principles on the incidence of spreadsheet errors. Accounting Education, 14(2), 199.

Ijiri, Y. (1983). New dimensions in accountng education: computers and algorithms. Issues in Accounting Education, 1, 168-173.

Kaplan, R. S. (1986). The role for empirical research in management accounting. Accounting, Organizations and Society, 11(4-5), 429-452.

Kelliher, C., Fogarty, T., \& Goldwater, P. (1996). Introducing uncertainty in the teaching of pensions: A simulation approach. Journal of Accounting Education, 14(1), 69.

Kent, P. F., \& Linnegar, G. H. (1988). Integrating Computers into Accounting Education: A Survey of Australian Universities and Colleges. Accounting and Finance, 28(2), 81.

Kruck, S., \& Maher, J. J. (1999). Home mortgage analysis for cultivating crucial spreadsheet and model development skills. Journal of Accounting Education, 17(2,3), 267. 
Lawrence, P. K., \& Rebecca, L. R. (2003). An investigation of the emerging trend towards a laptop requirement for accounting majors in the USA. Accounting Education, 12(4), 341.

Mabey, C., Topham, P., \& Kaye, G. R. (1998). Computer-based courseware: A comparative review of the learner's experience. Accounting Education, 7(1), 51.

Maher, J. J. (1993). Developing accounting-system concepts and computer skills with a spreadsheet program and a database manager. Issues in Accounting Education, 8(2), 404.

Mark, W. L., \& Clyde, E. H. (2003). Creating interactive spreadsheets to provide immediate feedback. Journal of Accounting Education, 21(4), 327.

Michelle, M. (2005). Game play in the learning environment: who wants to be an accountant? lawyer? economist? Accounting Education, 14(1), 95.

Moshen, S. (2003). Microsoft Excel for Accounting: Managerial and Cost. Issues in Accounting Education, 18(2), 223.

Neil, M. (2004). Using computerized business simulations and spreadsheet models in accounting education: a case study. Accounting Education, 13, 55.

Nia, L., \& Nadine, F. (2006). Accounting students' perceptions of a virtual learning environment: Springboard or safety net? Accounting Education, 15(2), 151.

Patricia, A. W. (2005). The Effect of Pension Income on the Quality of Corporate Earnings: IBM, A Case Study. Issues in Accounting Education, 20(2), 167.

Patton, M. Q. (2002). Qualitative research and evaluation methods. Thousand Oaks: Sage Publications.

Paul, M. G., \& Timothy, J. F. (2007). Protecting the Solution: A 'High-Tech.' Method to Guarantee Individual Effort in Accounting Classes. Accounting Education, 16(2), 129.

Philip, D. D., \& Mark, J. N. (2000). Computer assisted analytical procedures using Benford's Law. Journal of Accounting Education, 18(2), 127.

Rachlin, N. S. (1981). Ten Years of Change. Journal of Accountancy, 152(1), 32.

Read, N., \& Baston, J. (1999). Accountant's Digest: Spreadsheet modelling best practice. London: PriceWaterhouseCoopers.

Robert, N., Kurt, P., \& Jian, Z. (2002). Auditing with technology: Using generalized audit software in the classroom. Journal of Accounting Education, 20(4), 307.

Ryan, B., Scapens, R. W., \& Theobald, M. (1992). Research method and methodology in finance and accounting. London: Academic Press.

Satoshi, S., \& Gregory, B. (2006). The Effectiveness of PowerPoint presentations in the Accounting Classroom. Accounting Education, 15(4), 391.

Teets, W. R., \& Desmond, N. (1995). Anti-cheating 201: Preparing multiple versions of accounting exam problems through dynamic linking of word processing and spreadsheet programs. Journal of Accounting Education, 13(3), 343.

Theuri, P. M., \& Gunn, R. (1998). Accounting information systems course structure and employer systems skills expectations. Journal of Accounting Education, 16(1), 101.

Togo, D. F. (1992). A spreadsheet approach to stochastic financial modeling. Journal of Accounting Education, 10(2), 321.

Togo, D. F., \& McNamee, A. H. (1995). Computer integration into the accounting curriculum: Learning benefits, problems, and guidelines. Journal of Accounting Education, 13(2), 149.

Tracey, M., \& Beverley, J. (2006). The Impact of Computer-Assisted Learning on Academic Grades: An Assessment of Students' Perceptions. Accounting Education, 15(4), 377.

Ulric, J. G., Jr., Elliott, S. L., \& Jay, C. T. (2001). Norwood Office Supplies, Inc.: A teaching case to integrate computer-assisted auditing techniques into the auditing course. Issues in Accounting Education, 16(4), 603.

Vrasidas, C. (2000). Constructivism Versus Objectivism: Implications for Interaction, Course Design, and Evaluation in Distance Education. International Journal of Educational Telecommunications, 6(4), 339-362.

Yin, R., K. (2003). Case study research: Design and Methods (3rd ed.). Thousand Oaks: Sage Publications. 